\title{
Chapter 11 \\ Predicting Patterns of Plant Diversity and Endemism in the Tropics Using Remote Sensing Data: A Study Case from the Brazilian Atlantic Forest
}

\author{
Andrea Paz, Marcelo Reginato, Fabián A. Michelangeli, Renato Goldenberg, \\ Mayara K. Caddah, Julián Aguirre-Santoro, Miriam Kaehler, \\ Lúcia G. Lohmann, and Ana Carnaval
}

\subsection{Introduction}

The spatial distribution of species is unquestionably tied to environments, particularly temperature and precipitation (Hutchinson 1957). By exploring this correlation, multiple studies have demonstrated that environmental descriptors are able to predict geographic patterns of biological diversity reasonably well (Peters et al. 2016;

\footnotetext{
A. Paz $(\bowtie) \cdot$ A. Carnaval

Department of Biology, City College of New York, New York, NY, USA

Biology Program, The Graduate Center, City University of New York, New York, NY, USA

M. Reginato

Departamento de Botânica, Instituto de Biociências, Universidade Federal do Rio Grande do Sul, Porto Alegre, RS, Brazil

F. A. Michelangeli

Biology Program, The Graduate Center, City University of New York, New York, NY, USA

Institute of Systematic Botany, The New York Botanical Garden, The Bronx, NY, USA

R. Goldenberg

Universidade Federal do Paraná, Curitiba, PR, Brazil

M. K. Caddah

Universidade Federal de Santa Catarina, Florianopolis, SC, Brazil

J. Aguirre-Santoro

Biology Program, The Graduate Center, City University of New York, New York, NY, USA

Instituto de Ciencias Naturales, Facultad de Ciencias, Universidad Nacional de Colombia, Bogotá, Colombia

M. Kaehler · L. G. Lohmann

Departamento de Botânica, Instituto de Biociências, Universidade de São Paulo,

São Paulo, SP, Brazil
}

J. Cavender-Bares et al. (eds.), Remote Sensing of Plant Biodiversity, 
Zellweger et al. 2016). Temperature, for example, has been repeatedly shown to be a good predictor of the species that inhabit a given area (the taxonomic dimension of biodiversity, e.g., Peters et al. 2016). However, the power to predict the distinct dimensions of biodiversity varies within and across groups of organisms. For instance, the contribution of different measures of temperature and precipitation appears to be idiosyncratic when multiple taxa are compared (Rompré et al. 2007; Laurencio and Fitzgerald 2010; Peters et al. 2016; Zellweger et al. 2016). Moreover, and in contrast to species richness (SR), the relationships between climate and the geographic distribution of evolutionary diversity in a region (i.e., the phylogenetic dimension of biodiversity), as well as the relationships between climate and endemism, have been less explored. Still, those relationships appear weaker due to the relatively larger contribution of history, biogeography, and contingency in the spatial distribution of lineages (da Silva et al. 2012; Barratt et al. 2017).

Most of those advances have relied on the use of climatic data sets that are interpolated from weather station data (Hijmans et al. 2005), summarizing spatial patterns of temperature and precipitation. These include the widely used WorldClim data set (Hijmans et al. 2005), country-specific data sets (e.g., Cuervo-Robayo et al. 2014), and the hybrid CHELSA database (Karger et al. 2017). The ease by which biodiversity scientists can access and download these databases, and the fact that they provide global-scale climatic information at biologically relevant scales (up to $1 \mathrm{~km}$ ), have resulted in a sharp increase in the number of studies that explore the correlations between climate and biodiversity patterns. Yet the accuracy and the effectiveness of these global climatic descriptors have been questioned (Soria-Auza et al. 2010). Because the distribution of weather stations around the world is unequal, the confidence in those data sets is reduced in undersampled areas, which frequently correspond to the most biodiverse areas on Earth (see Pinto-Ledézma and CavenderBares, Chap. 9).

In this chapter, we explore the use of bioclimatic variables built from long-term climatologies derived from remote sensing (RS) as predictors of biodiversity patterns. We focus in a megadiverse region, with high topographic complexity: the Brazilian Atlantic Forest hotspot. We evaluate whether climate, inferred from RS sources, predicts which areas accumulate the highest diversity of species, evolutionary lineages, and endemism. For that, we use distribution and phylogenetic data from three plant clades representing different life forms, that are commonly found in the Brazilian Atlantic Forest: melastomes (178 species of shrubs and trees), bromeliads (43 species of epiphytes), and bignones (131 species of lianas). We also evaluate what (if any) gains emerge from the use of climatic descriptors based on RS, rather than weather stations, for this area. Given the sharp altitudinal changes observed in the Brazilian Atlantic Forest hotspot, it has been proposed that interpolated weather station data may perform more poorly than variables derived from RS (Waltari et al. 2014). 


\subsection{Study System}

The Brazilian Atlantic Forest harbors one of the highest levels of endemism and threat globally, representing one the world's hotspots of biodiversity (Myers et al. 2000). Although only about $16 \%$ of the original forest persists (Ribeiro et al. 2009), the Atlantic Forest is topographically and environmentally complex, spanning more than $1,700 \mathrm{~m}$ in altitude and about $25^{\circ}$ of latitude (Ribeiro et al. 2009). Climatic analyses of the forest, along with molecular studies of its biota, suggest that it encompasses multiple environmental spaces and associated species pools. More specifically, the northern (mostly lowland) and southern (mostly montane) elements are largely different in species composition and have responded differently to past climatic changes (Carnaval et al. 2014; Leite et al. 2016).

Melastomes represent the first clade selected for our study. The tribe Miconieae (Melastomataceae) is exclusively Neotropical, with ca. 1,900 species, mostly shrubs and small trees, but also herbs, lianas, epiphytes, and large trees (Michelangeli et al. 2004, 2008; Goldenberg et al. 2008). In the Atlantic Forest, the tribe is represented by ca. 310 species, $70 \%$ of which are endemic ("Flora do Brasil 2020"; Goldenberg et al. 2009). These species are largely grouped into three clades: the Leandra clade with ca. 215 species (Caddah 2013; Reginato and Michelangeli 2016), the Miconia section Chaenanthera clade (Goldenberg et al. 2018), and the Miconia sect. discolor clade. Most of these species are small trees and shrubs (although the Pleiochiton clade contains 12 species of shrubby epiphytes; Reginato et al. 2010, 2013), and the great majority are bee pollinated and have berry fruits that are dispersed by birds. In the Atlantic Forest, species of Miconieae are found throughout most environments and at all elevations, with species ranges varying from widely distributed within the domain and beyond, to microendemics found in a single mountain top (Michelangeli et al. 2008).

Bromeliads represent the second clade included in this investigation. The Bromeliaceae is an almost exclusively Neotropical family, with ca. 3,300 species of terrestrial or epiphytic rosette-forming herbs. In the Atlantic Forest, the Bromeliaceae is represented by 816 species, over $75 \%$ of which are endemic (Martinelli et al. 2009). The data set used here represents a clade of 70 species belonging to the Ronnbergia-Wittmackia alliance (Aguirre-Santoro et al. 2016; Aguirre-Santoro 2017). With the exception of one species, the basal grade of 26 species of Wittmackia is composed of species restricted to the Atlantic Forest. All of them are tank-forming epiphytes found in forested environments, many with very restricted distributions (Aguirre-Santoro 2017). In the Atlantic Forest, Wittmackia is found predominantly in the central and northern states.

Bignones are the third plant clade used in this analysis. The tribe Bignonieae (Bignoniaceae) originated at around 50 million years ago (mya) in the Brazilian Atlantic Forest and subsequently occupied Amazonia and the dry areas of Central Brazil (Lohmann et al. 2013). The group is very diverse ecologically, including species pollinated by hummingbirds, butterflies, bees, and bats (Gentry 1974; Alcantara and Lohmann 2010). Ant-plant interactions are extremely common and play an 
important role in herbivore defense (Nogueira et al. 2015). Most species in the family are dispersed by wind or water (Lohmann 2004).

Former drying of Neotropical climates, and the Andean orogeny, seems to have represented key diversification drivers for tribe Bignonieae (Lohmann et al. 2013). Today, it includes 383 species and 21 genera (Lohmann and Taylor 2014), representing the most diverse and abundant clade of lianas in Neotropical forests (Lohmann 2006). All species of the tribe are distributed among three main clades:

(i) the "multiples of four clade" (referring to the multiples of four phloem wedges), with ca. 135 species (Lohmann 2006); (ii) the "Fridericia and Allies clade," with around 132 species (Kaehler et al. 2019); and (iii) the "Adenocalymma-Neojobertia" clade, with ca. 75 species (Fonseca and Lohmann 2018). The remaining species of the Tribe are distributed among eight small genera (Lohmann 2006).

\subsection{Methods}

To investigate the relationships between climate and biodiversity patterns in the Atlantic rainforest of Brazil, we selected three clades of angiosperms with different life forms, i.e., shrubs and small trees (tribe Miconieae, Melastomataceae), epiphytic herbs (the Ronnbergia/Wittmackia alliance, Bromeliaceae), and lianas (the "Fridericia and Allies" clade of tribe Bignonieae, Bignoniaceae).

For each group, we combined geo-referenced occurrence data from each species with information about its evolutionary relationships. Using personal field data, published records, and geo-referenced herbarium information, we gathered locality information for 352 species and 22,338 unique locality points vetted by experts for spatial and taxonomic accuracy as follows: (i) melastomes, 178 species and 10,253 records of members of tribe Miconieae; (ii) bromeliads, 43 species and 4,606 records of members of the Ronnbergia/Wittmackia alliance; and (iii) Bignones, 132 species and 7,480 records of members of the "Fridericia and Allies" clade of tribe Bignonieae (Lohmann, unpublished data; see Meyer et. al 2008 for further details on this data set).

For each species, we used the locality data to generate a multiple convex polygon representing its range, which was then converted into a gridded map ( $\sim 5 \mathrm{~km}$ resolution). Maps of the individual species were then stacked, allowing us to compute the total number of species per pixel. Information about the species composition at each grid cell was then combined with published and novel data on the phylogenetic relationships among species of melastomes (Caddah 2013; Reginato and Michelangeli 2016; Goldenberg et al. 2018), bromeliads (Aguirre-Santoro et al. 2016), and bignones (Kaehler et al. 2019), to provide a measurement of phylogenetic diversity (PD) per pixel, using Faith's phylogenetic diversity index (Faith 1992). This metric quantifies the evolutionary history included in every community by adding the branch lengths leading to each taxon present in the community (Faith 1992).

We also identified pixels holding high or low levels of phylogenetic endemism (PE) by including information about the range of each species' sister taxon 
(PE, Rosauer et al. 2009). This metric takes into account the evolutionary history (as branch lengths) and spatial restriction (here as range estimates; Rosauer et al. 2009). To allow for comparisons across plant groups with distinct life histories and environmental envelopes, we performed these analyses separately for each clade (melastomes, bromeliads, and bignones). We used the Biodiverse software (Laffan et al. 2010) to map the geographical patterns of SR, the PD, and the phylogenetic endemism of each group.

We then gathered climatic descriptors for the Atlantic Forest region using two sources of climatic data, both at a $0.05^{\circ}$ resolution $(\sim 5 \mathrm{~km})$ : one derived from RS instruments (Deblauwe et al. 2016) and another derived from interpolated weather station data (WorldClim database; Hijmans et al. 2005). Both databases describe environmental variation in the form of 19 bioclimatic variables that reflect spatial and temporal differences in precipitation and temperature (Bio1-19, as defined in the WorldClim database). These data were estimated with the same formulae, across data sets. While the WorldClim data reflect bioclimatic conditions estimated from interpolated weather station information, the database of Deblauwe et al. (2016) was built based on temperature information from NASA's Moderate Resolution Imaging Spectroradiometer (MODIS) and precipitation from the Climate Hazards Group InfraRed Precipitation with Station (CHIRPS) data. To reduce collinearity between the 19 bioclimatic variables, we employed a variance inflation factor (VIF), retaining only those variables with VIF $<5$ in both datasets in all analyses. This left us with seven variables from each source, in both cases bio 3, 8, 9 13,18, and 19, plus bio 2 for the dataset based on weather station data (WorldClim), and bio 7 for the RS-based (Deblauwe et al. 2016) dataset (see Table 11.1 for bioclimatic variable descriptions).

To investigate how much of the spatial patterns of SR, PD, and phylogenetic endemism can be explained by each set of climatic descriptors, we ran conditional autoregressive (CAR) models on the pooled data from each group. CAR models

Table 11.1 Bioclimatic variables used as predictors for analyses, after removing variables with high variance inflation factor (VIF)

\begin{tabular}{l|l}
\hline Variable & Description \\
\hline Bio 2 & $\begin{array}{l}\text { Mean diurnal range [mean of monthly } \\
\text { (max temp-min temp)] }\end{array}$ \\
\hline Bio 3 & Isothermality (Bio 2/Bio 7) $* \mathbf{1 0 0}$ \\
\hline Bio 7 & Temperature annual range \\
\hline Bio 8 & $\begin{array}{l}\text { Mean temperature of the wettest } \\
\text { quarter }\end{array}$ \\
\hline Bio 9 & $\begin{array}{l}\text { Mean temperature of the driest } \\
\text { quarter }\end{array}$ \\
\hline Bio 13 & Precipitation of the wettest month \\
\hline Bio 18 & Precipitation of the warmest quarter \\
\hline Bio 19 & Precipitation of the coldest quarter \\
\hline
\end{tabular}

In bold, variables used in both the RS- and weather station-derived data sets

Bio 2 was used only in the weather station-based analysis; bio 7 was used only in the RS-based analysis 
implement a multiple spatial regression in which the covariance among residuals considers the neighborhood of each evaluated cell (Rangel et al. 2006). To evaluate model fit, we computed pseudo- $R^{2}$ for our models, including both the full model and the predictor-only effect (i.e., removing the effect of space and spatial autocorrelation). Also, to detect areas of potential concentration or overdispersion of the regression residuals, we generated residual maps for models of SR and PD.

\subsection{Results and Discussion}

The spatial patterns of SR, PD, and phylogenetic endemism vary across groups. While melastomes show higher PD and SR along the east coast of Brazil, bromeliads accumulate PD and SR in the northern region of the Atlantic Forest, and bignones in the central portion of the domain. Phylogenetic endemism concentrates in the coastal mountains for melastomes, in the northern coast for bromeliads, and toward the west and northwest for bignones (Fig. 11.1).

Bioclimatic variables derived from RS products have excellent predictive power for both SR and PD. The full CAR models built from RS sources performed well, irrespective of plant group $\left(R^{2}>0.89\right.$, Table 11.2). Prediction of phylogenetic ende-
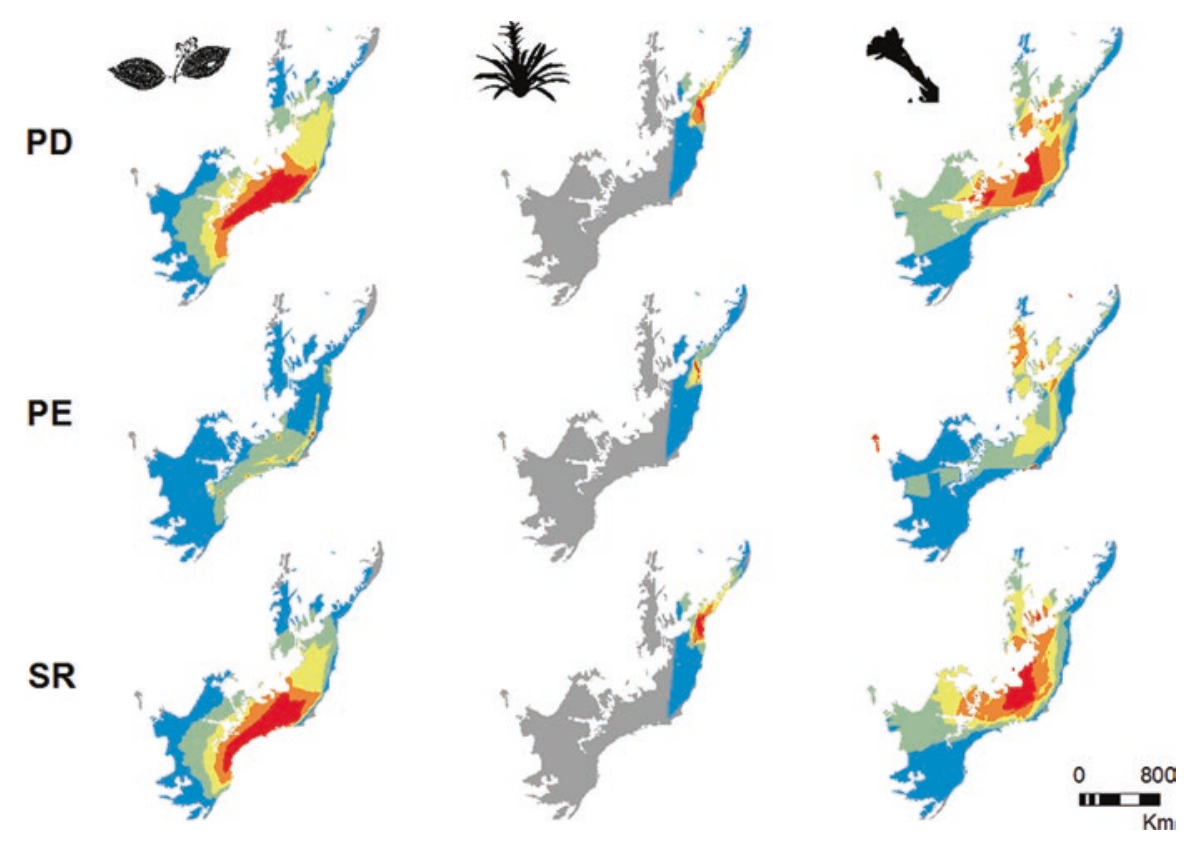

Fig. 11.1 Patterns of biodiversity for three plant clades in the Brazilian Atlantic Forest, from left to right: melastomes, bromeliads, and bignones. Each row corresponds to one biodiversity index, top to bottom: phylogenetic diversity (PD), phylogenetic endemism (PE), and species richness (SR). Warmer colors represent higher values of each of the indices 
Table 11.2 Predictive power of models using either RS-based variables (RS) or weather stationderived variables (WC) as predictors of phylogenetic diversity (PD), phylogenetic endemism (PE), and species richness (SR) in three plant clades from the Brazilian Atlantic Forest: melastomes, bromeliads, and bignones

\begin{tabular}{|c|c|c|c|c|}
\hline Clade & Predictors & Predicted & Full model $R^{2}$ & Non-space $R^{2}$ \\
\hline \multirow[t]{6}{*}{ Melastomes } & \multirow[t]{3}{*}{$\mathrm{RS}$} & PD & 0.96 & 0.61 \\
\hline & & $\mathrm{PE}$ & 0.62 & 0.01 \\
\hline & & SR & 0.97 & 0.61 \\
\hline & \multirow[t]{3}{*}{ WC } & PD & 0.96 & 0.57 \\
\hline & & $\mathrm{PE}$ & 0.62 & 0.02 \\
\hline & & SR & 0.96 & 0.55 \\
\hline \multirow[t]{6}{*}{ Bromeliads } & \multirow[t]{3}{*}{$\mathrm{RS}$} & PD & 0.91 & 0.37 \\
\hline & & $\mathrm{PE}$ & 0.75 & 0.03 \\
\hline & & SR & 0.92 & 0.37 \\
\hline & \multirow[t]{3}{*}{ WC } & PD & 0.88 & 0.19 \\
\hline & & $\mathrm{PE}$ & 0.74 & 0.02 \\
\hline & & SR & 0.89 & 0.19 \\
\hline \multirow[t]{6}{*}{ Bignones } & \multirow[t]{3}{*}{$\mathrm{RS}$} & PD & 0.94 & 0.58 \\
\hline & & $\mathrm{PE}$ & 0.57 & 0.10 \\
\hline & & SR & 0.96 & 0.72 \\
\hline & \multirow[t]{3}{*}{ WC } & PD & 0.94 & 0.59 \\
\hline & & $\mathrm{PE}$ & 0.57 & 0.10 \\
\hline & & SR & 0.96 & 0.74 \\
\hline
\end{tabular}

Numbers in bold have higher predictive power when comparing RS and WC for a single group

mism based on RS sources was not as successful: the performance of the CAR models was fair to good, irrespective of plant clade $\left(R^{2} 0.57-0.75\right.$, Table 11.2$)$. These observed differences in predictive power are not surprising and stand in agreement with the expectation that phylogenetic endemism may be more strongly impacted by historical processes and former climates (e.g., Late Quaternary) than by contemporary descriptors (Rosauer and Jetz 2015).

The predictive power of the models built with weather station data (WorldClim; Hijmans et al. 2005) was comparable to that of models based on satellite information, similar to Pinto-Ledézma and Cavender-Bares (Chap. 9), showing only slightly lower $R^{2}$ values overall (within 0.01, Table 11.2). This difference tended to increase (i.e., with models based on RS data performing better than those built with weather station data) when spatial autocorrelation effects were removed from the analyses (Table 11.2).

Climatic descriptors derived from both RS information (Deblauwe et al. 2016) and weather station data (Hijmans et al. 2005) failed to predict spatial patterns of phylogenetic endemism (PE) when decoupled from space $\left(R^{2} 0.01-0.1\right.$, Table 11.2). Geography is naturally expected to impact maps of endemism because this analysis of geographical restriction of evolutionary history explicitly incorporates space in its calculations (Rosauer et al. 2009). Still, when this spatial imprint is removed from the data, we notice that contemporary climates are unable to predict the distribution 
of lineage restriction - in agreement with previous suggestions that historical climates, or the stochasticity of the processes associated with colonization or extinction, may have an important role in determining phylogenetic endemism (Carnaval et al. 2014; Rosauer and Jetz 2015).

Although the performance of the CAR models varied across diversity measures and taxa, the analyses decoupled from space recovered consistently lower predictive power in bromeliads, irrespective of diversity measures (Table 11.2). Unlike the other two groups, this clade is composed mainly of microendemics and represented only in a relatively small region of the Atlantic Forest (Fig. 11.1). We hypothesize that the larger influence of space, history, and chance events (particularly related to local extinctions) may be responsible for the lower correspondence between spatial patterns of biodiversity and climatic descriptors in groups of species that are narrowly distributed. This being true, it is expected that the predictive power of correlative models of biodiversity such as those presented here-including the use of RS data-will perform best in tropical groups in which most species have relatively large ranges.

The spatial distribution of the residuals of the correlation between biodiversity metrics and climate data differed across clades. In melastomes, they were homogeneously distributed across the forest, while for both bromeliads and bignones large residuals of SR and PD were observed in areas with low overall diversity. In bignones, residuals were especially concentrated in the south-where large geographic extensions showed more or less PD than expected (Fig. 11.2). Particularly the southern portion of the forest shows higher PD of bignones than expected, given the models based on climate data. This may be related to these plants' sensitivity to altitude, which limits their growth (Lohmann, pers. obs.). Bignoniaceae species are sensitive to temperature and precipitation, with abundance and species richness responding positively in warmer climates, and strongly negative in wetter climates. Thus, the species richness, or phylogenetic diversity, is increased in warmer and drier dry-season habitats (Punyasena et al. 2008). The south of the Atlantic forest is montane and the areas with larger residuals in South Brazil have dry, though cool winters. Given that no topographic variables were included in our models, this overprediction appears reasonable.

\subsection{Conclusions and Future Directions}

Community-level data from three representative tropical plant groups that include lianas, shrubs, and trees demonstrate that the use of RS data describing temperature and precipitation accurately predicts the spatial distribution of two essential biodiversity metrics (SR and PD) in a biodiversity hotspot. This predictive power is reduced when the approach is applied to a clade of spatially restricted (narrow endemic) species, such as bromeliads. Across all plant groups, predictive power is lower for diversity indices highly influenced by historical contingency and spatial configuration, such as phylogenetic endemism. For predictive purposes, and at the 


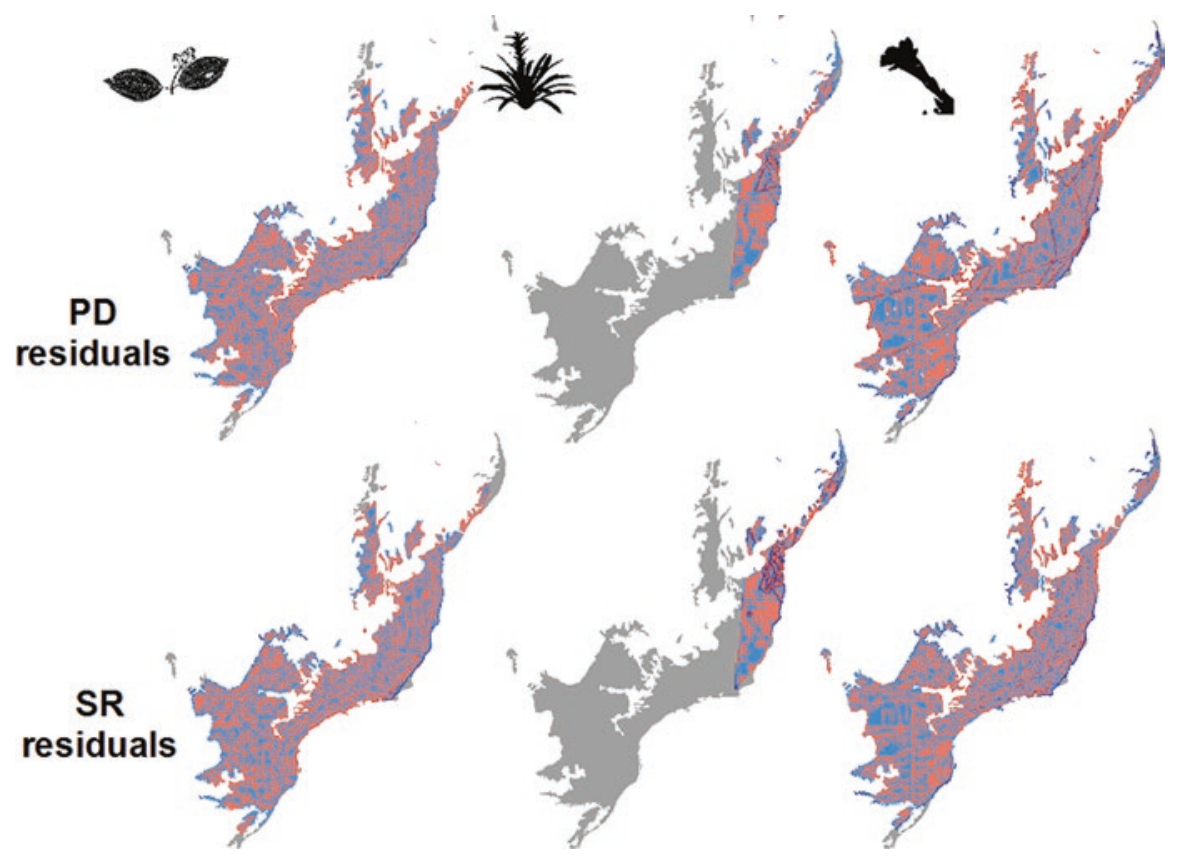

Fig. 11.2 Residuals of the CAR models using remote sensing variables as predictors of phylogenetic diversity (PD) and species richness (SR) for three groups of plants from the Brazilian Atlantic Forest, from left to right: melastomes, bromeliads, and bignones. Blue denotes areas with negative residuals (sites where less diversity is observed than expected under the model). Areas with positive residuals are shown in red. Darker shades of blue and red represent larger residuals

spatial scale of the Atlantic Forest, the performance of RS-based climate descriptors is comparable to, or slightly better than, that of weather station-based databases. These results show promise for predicting different dimensions of diversity in the tropics, based on RS data, especially for widely distributed groups. This approach may be particularly relevant in groups or regions for which direct or indirect species identification through RS (e.g., hyperspectral images) is feasible or available. It also may be extended to other groups of plants, and to animals. Future directions of this work include testing whether RS-based predictions of biodiversity work similarly well in other biological groups, biomes, and geographical areas, while also potentially including additional variables of interest, such as topography and historical climates.

\section{References}

Aguirre-Santoro J (2017) Taxonomy of the Ronnbergia Alliance (Bromeliaceae: Bromelioideae): new combinations, synopsis, and new circumscriptions of Ronnbergia and the resurrected genus Wittmackia. Plant Syst Evol 303:615-640 
Aguirre-Santoro J, Stevenson D, Michelangeli F (2016) Molecular phylogenetics of the Ronnbergia Alliance (Bromeliaceae, Bromelioideae) and insights about its morphological evolution. Mol Phylogenet Evol 100:1-20

Alcantara S, Lohmann LG (2010) Evolution of floral morphology and pollination system in Bignonieae (Bignoniaceae). Am J Bot 97:782-796

Barratt CD, Bwong BA, Onstein RE et al (2017) Environmental correlates of phylogenetic endemism in amphibians and the conservation of refugia in the Coastal Forests of Eastern Africa. Divers Distrib 23:875-887

Caddah M (2013) Estudos Taxonomicos e filogenéticos em Miconia sect. Discolor (Melastomataceae, Miconieae). PhD thesis. UNICAMP, Campinas

Carnaval AC, Waltari E, Rodrigues MT et al (2014) Prediction of phylogeographic endemism in an environmentally complex biome. Proc R Soc B Biol Sci 281:20141461

Cuervo-Robayo AP, Téllez-Valdés O, Gómez-Albores MA et al (2014) An update of highresolution monthly climate surfaces for Mexico. Int J Climatol 34:2427-2437

da Silva FR, Almeida-Neto M, do Prado VHM, Haddad CFB, de Cerqueira Rossa-Feres D (2012) Humidity levels drive reproductive modes and phylogenetic diversity of amphibians in the Brazilian Atlantic Forest. J Biogeogr 39:1720-1732

Deblauwe V, Droissart V, Sonke B et al (2016) Remotely sensed temperature and precipitation data improve species distribution modelling in the tropics. Glob Chang Biol 25(4):443-454

Faith DP (1992) Conservation evaluation and phylogenetic diversity. Biol Conserv 61:1-10

Flora do Brasil 2020 Jardim Botânico do Rio de Janeiro

Fonseca L, Lohmann LG (2018) Combining high-throughput sequencing and targeted loci data to infer the phylogeny of the "Adenocalymma-Neojobertia" clade. Mol Phylogenet Evol 123:1-15

Gentry AH (1974) Coevolutionary patterns in Central American Bignoniaceae. Ann Mo Bot Gard 61:728-759

Goldenberg R, Penneys DS, Almeda F, Judd WS, Michelangeli F (2008) Phylogeny of Miconia (Melastomataceae): initial insights into broad patterns of diversification in a megadiverse neotropical genus. Int J Plant Sci 169:963-979

Goldenberg R, Guimarāes P, Kriebel R, Romero R (2009) Melastomataceae. In: Stehmann JR, Forzza R, Salino A et al (eds) Plantas da Floresta Atlantica. Instituto de Pesquisas Jardim Botânico do Rio de Janeiro, Rio de Janeiro, pp 330-343

Goldenberg R, Reginato M, Michelangeli F (2018) Disentangling the infrageneric classification of megadiverse taxa from Mata Atlantica: phylogeny of Miconia section Chaenanthera (Melastomataceae. Miconieae). Taxon 67:537-551

Hijmans RJ, Cameron SE, Parra JL, Jones PG, Jarvis A (2005) Very high resolution interpolated climate surfaces for global land areas. Int J Climatol 25:1965-1978

Hutchinson (1957) Concluding remarks. Cold Spring Harb Symp Quant Biol 22:415-427

Kaehler M, Michelangeli FA, Lohmann LG (2019) Fine-tuning the circumscription of Fridericia (Bignonieae, Bignoniaceae). Taxon 68(3). https://doi.org/10.1002/tax.12121

Karger DN, Conrad O, Böhner J et al (2017) Data descriptor: climatologies at high resolution for the earth's land surface areas. Scientific Data 4:1-20

Laffan SW, Lubarsky E, Rosauer DF (2010) Biodiverse, a tool for the spatial analysis of biological and related diversity. Ecography 33:643-647

Laurencio D, Fitzgerald LA (2010) Environmental correlates of herpetofaunal diversity in Costa Rica. J Trop Ecol 26:521-531

Leite YLR, Costa LP, Loss AC et al (2016) Neotropical forest expansion during the last glacial period challenges refuge hypothesis. Proc Natl Acad Sci 113:1008-1013

Lohmann LG (2004) Bignoniaceae. In: Smith N, Mori S, Henderson A, Stevenson SH (eds) Flowering plants of the neotropics. Princeton University Press, Princeton, pp 51-53

Lohmann LG (2006) Untangling the phylogeny of neotropical lianas (Bignonieae, Bignoniaceae). Am J Bot 93:304-318

Lohmann LG, Taylor CM (2014) A new generic classification of tribe Bignonieae (Bignoniaceae). Ann Mo Bot Gard 99:348-489 
Lohmann LG, Bell CD, Calió MF, Winkworth RC (2013) Pattern and timing of biogeographical history in the Neotropical tribe Bignonieae (Bignoniaceae). Bot J Linn Soc 171:154-170

Martinelli G, Vieira C, Leitman P, Costa A, Forzza R (2009) Bromeliaceae. In: Stehmann JR, Forzza R, Salino A et al (eds) Plantas da Floresta Atlantica. Instituto de Pesquisas Jardim Botânico do Rio de Janeiro, Rio de Janeiro, pp 186-204

Meyer L, Diniz-Filho JAF, Lohmann LG (2008) A comparison of hull methods for estimating species ranges and richness maps. Plant Ecol Diversity 10:389-401

Michelangeli F, Penneys D, Giza J et al (2004) A preliminary phylogeny of the tribe Miconieae (Melastomataceae) based on nrlITS sequence data and its implications on inflorescence position. Taxon 53:279-290

Michelangeli F, Judd WS, Penneys DS et al (2008) Multiple events of dispersal and radiation of the tribe Miconieae (Melastomataceae) in the Caribbean. Bot Rev 74:53-77

Myers N, Mittermeier RA, Mittermeier CG, da Fonseca GAB, Kent J (2000) Biodiversity hotspots for conservation priorities. Nature 403:853-858

Nogueira A, Rey P, Alcántara J, Feitosa R, Lohmann LG (2015) Geographic mosaic of plant evolution: Extrafloral nectary variation mediated by ant and herbivore assemblages. PLoS One 10:e123806

Peters MK, Hemp A, Appelhans T et al (2016) Predictors of elevational biodiversity gradients change from single taxa to the multi-taxa community level. Nat Commun 7:13736

Punyasena SW, Eshel G, McElwain JC (2008) The influence of climate on the spatial patterning of Neotropical plant families. J Biogeogr 35:117-130

Rangel TFLVB, Diniz-Filho JAF, Bini LM (2006) Towards an integrated computational tool for spatial analysis in macroecology and biogeography. Glob Ecol Biogeogr 15:321-327

Reginato M, Michelangeli F (2016) Untangling the phylogeny of Leandra sensu str. (Melastomataceae, Miconieae). Mol Phylogenet Evol 96:17-32

Reginato M, Michelangeli F, Goldenberg R (2010) Phylogeny of Pleiochiton A. Gray (Melastomataceae, Miconieae): total evidence. Bot J Linn Soc 162:423-434

Reginato M, Baumgratz J, Goldenberg R (2013) A taxonomic revision of Pleiochiton (Melastomataceae, Miconieae). Brittonia 65:16-41

Ribeiro MC, Metzger JP, Martensen AC, Ponzoni FJ, Hirota MM (2009) The Brazilian Atlantic Forest: how much is left, and how is the remaining forest distributed? Implications for conservation. Biol Conserv 142:1141-1153

Rompré G, Robinson WD, Desrochers A, Angehr G (2007) Environmental correlates of avian diversity in lowland Panama rain forests. J Biogeogr 34:802-815

Rosauer DF, Jetz W (2015) Phylogenetic endemism in terrestrial mammals. Glob Ecol Biogeogr 24:168-179

Rosauer D, Laffan SW, Crisp MD, Donnellan SC, Cook LG (2009) Phylogenetic endemism: a new approach for identifying geographical concentrations of evolutionary history. Mol Ecol 18:4061-4072

Soria-Auza RW, Kessler M, Bach K et al (2010) Impact of the quality of climate models for modelling species occurrences in countries with poor climatic documentation: a case study from Bolivia. Ecol Model 221:1221-1229

Waltari E, Schroeder R, McDonald K, Anderson RP, Carnaval A (2014) Bioclimatic variables derived from remote sensing: assessment and application for species distribution modelling. Methods Ecol Evol 5:1033-1042

Zellweger F, Baltensweiler A, Ginzler C et al (2016) Environmental predictors of species richness in forest landscapes: abiotic factors versus vegetation structure. J Biogeogr 43:1080-1090 
Open Access This chapter is licensed under the terms of the Creative Commons Attribution 4.0 International License (http://creativecommons.org/licenses/by/4.0/), which permits use, sharing, adaptation, distribution and reproduction in any medium or format, as long as you give appropriate credit to the original author(s) and the source, provide a link to the Creative Commons license and indicate if changes were made.

The images or other third party material in this chapter are included in the chapter's Creative Commons license, unless indicated otherwise in a credit line to the material. If material is not included in the chapter's Creative Commons license and your intended use is not permitted by statutory regulation or exceeds the permitted use, you will need to obtain permission directly from the copyright holder. 